\title{
24
}

\section{Mindfulness in Education: Insights Towards an Integrative Paradigm}

\author{
Nimrod Sheinman and Pninit Russo-Netzer
}

\section{Introduction}

Within the past few decades, an increased interest in the concepts and applications of mindfulness in education has generated an extensive range of initiatives, programs, and delivery approaches worldwide. Explorations, applications, integrations, and research projects of mindfulness in education have become prevalent in schools, kindergartens, schools of education, teacher inservice trainings, and higher education. Mindfulness was introduced into the education field in hopes of enhancing wellbeing, mental health, social and emotional skills, resilience, prosocial behaviour, and academic performance. The number of peer-reviewed publications relating to mindfulness in education is rising exponentially, and the topic is being discussed in international bodies such as the United Nations Educational, Scientific, and Cultural Organization (UNESCO), The Organization for Economic Co-operation and Development (OECD), the World Bank, and the World Economic Forum.

The interest in mindfulness and its benefits has expanded since it was first introduced into medicine at the end of the 1970s to help people with chronic health issues cope with their pain, stress, and illness. Originally an

\footnotetext{
N. Sheinman $(\bowtie)$

Israel Center for Mindfulness in Education, Kadima, Israel

P. Russo-Netzer

Achva Academic College, Arugot, Israel

University of Haifa, Haifa, Israel
} 
integrated element of Buddhist practices, mindfulness was transformed into a secularized intervention, delivered in groups, and aimed at reducing stress and promoting wellbeing (Kabat-Zinn, 2003; Segal, Williams, \& Teasdale, 2013). The research, clinical success, and prevalence of the model led to an expanded interest in mindfulness-based perspectives and inspired subsequent generations of therapeutic and non-therapeutic models.

A sequel to this unfolding evolution has been the rise of mindfulnessbased programs within educational settings, which began at the end of the 1990s (Ergas \& Hadar, 2019; Meiklejohn et al., 2012; Semple, Droutman, \& Reid, 2017). Within this domain, initiatives and prototypes were developed, applied, and researched in diverse educational contexts in North America, Europe, Asia, Australia, New Zealand, South America, and Africa (Ergas \& Hadar, 2019).

Altogether, the collective empirical and published data demonstrate that mindfulness in education can be framed and implemented in a variety of ways, applied towards various aims, deliver a multitude of potential outcomes, and support the betterment of both students and teachers (Ergas \& Hadar, 2019; Felver \& Jennings, 2016). Embedded in these many approaches are assumptions about the goals of education, the role of mindfulness-based pedagogies in it, how mindfulness should be taught, who should deliver it, and how to evaluate outcomes.

Mindfulness in education is in congruence with many principles and visions of positive psychology. This chapter presents an overview of mindfulness in education around the world and summarizes the knowledge accumulated from various perspectives and practices worldwide. The chapter centres mostly on the learners' domain (school-age children, 6-18 years old), with reference to the role of educators. It describes the evolution of mindfulness in education and its role within a holistic and integrative future education paradigm. Relevant and conceivable relationship with positive education is discussed.

\section{Mindfulness and Its Origins}

The word mindfulness is an English translation of the word sati, which occurs in Buddhist teachings and texts in a range of meanings, such as recollection, recognition, wakefulness, attentiveness, calling to mind, and alertness (Bodhi, 2011; Ditrich, 2017). In the context of contemplative practices, it refers to a quality of conscious awareness, and the repeated application of this awareness to each experience of life (Bodhi, 2011; Ditrich, 
2017). Furthermore, the term relates to the cultivation of wholesome, skilful, wise attention to four domains of existence: body, feelings, cognition, and mental constituents. According to the traditional Buddhist teachings, mindfulness strengthens tranquillity and mental balance and enhances wisdom, insight, loving-kindness, and compassion. Further, the meditation practices are assumed to bring about a reduction of greed, aversion, and ignorance, considered by Buddhist psychology to be at the root of human suffering (Ditrich, 2017).

Many of these perspectives were introduced to the West since the 1960s and 1970s, through Westerners travelling to Asia to study Buddhist practices, and Buddhist teachers from the East visiting the West. Buddhist centres that were subsequently founded, especially in the U.S. and England, integrated various Eastern traditions and offered programs and trainings to the general public (Young, 2016).

The aims of these methods, as conceptualized then, were described as the cultivation of profound insight into mental processes, identity, and reality, and the development of an optimal state of psychological wellbeing and consciousness (Walsh, 1983). Meditations were seen as a family of practices that train attention, heighten awareness, and bring mental processes under greater voluntary control. The discourse of the time identified the methods as potentially beneficial for a variety of "intermediate aims", such as psychophysiological and psychotherapeutic (Walsh, 1983). Thus, the foundation for the secularization of the original spiritual practices was prepared.

A significant step in the secularization of mindfulness appeared with the introduction of the Mindfulness-Based Stress Reduction (MBSR) program in late 1970. The model, developed by Kabat-Zinn, was incorporated into the University of Massachusetts' (U.S.) stress reduction clinic and was targeted to assist patients in coping with their stress, pain, and illness. The MBSR format transforms the Buddhist methods into an eight-week group session protocol (initially nine), integrating guided mindfulness-based practices, psychoeducation, group discussions, and regular home practice. The experiential sessions include various sitting and lying practices, such as breath awareness and body scan, as well as mindful yoga exercises, mindful walking, and mindful eating experiences (Kabat-Zinn, 1990). The model modified the ancient principles and practices, reframing and presenting them as a therapeutic protocol.

The secularization of mindfulness, and its introduction into the medical and psychotherapeutic domains, has inevitably been reflected in new conceptualizations. Secular mindfulness is most commonly defined as the awareness that emerges through paying attention on purpose, in the present moment, and non-judgementally, to the unfolding of experience moment by moment 
(Kabat-Zinn, 2003), or as a non-elaborative, non-judgemental, presentcentred awareness, in which each thought, feeling, or sensation that arises in the attentional field is acknowledged and accepted as it is (Bishop et al., 2004).

The MBSR model led to the emergence of other clinical models, most notably the Mindfulness-Based Cognitive Therapy (MBCT), which incorporates cognitive strategies into the MBSR protocol. The MBCT approach uses an 8-week, group-based structure and is advocated mostly for patients with a history of depression (Segal et al., 2013). In addition to MBSR and MBCT, mindfulness-based techniques have also been integrated into several one-onone psychotherapeutic systems, such as Dialectic Behavioural Therapy (DBT) and Acceptance and Commitment Therapy (ACT) (Shonin, Van Gordon, \& Griffiths, 2013).

Concurrent adaptations of mindfulness-based approaches across the world led to numerous mindfulness-based modifications, including applications for emotional balance (Cullen \& Pons, 2015), medical conditions (e.g., Carlson, 2012; Greeson \& Chin, 2019), psychotherapy (Germer et al., 2016; Pollak, Pedulla, \& Siegel, 2014; Rappaport, 2008), trauma therapy (Schwartz, 2013; Weiss, Johanson, \& Monda, 2015), leadership (Arendt, Verdorfer, \& Kugler, 2019), workplace (Bartlett et al., 2019; King, 2019), and politics (Bristow, 2019). Moreover, mindfulness became an investigated topic in neuroscience (Tang, Hölzel, \& Posner, 2015), immunity research (Black \& Slavich, 2016), epigenetics (Kaliman, 2019; Kaliman et al., 2014), and self-compassion (Ferrari et al., 2019; Germer \& Neff, 2013) studies. Accordingly, the number of peer-reviewed papers per year grew exponentially, from zero publications in 1980 to almost 850 publications in 2018 (Black, 2018).

The main arena in which mindfulness-based principles are rapidly growing is the education field, where mindfulness has been integrated to foster children's (and teachers') mental, emotional, and behavioural health, and to promote essential life skills. School-based mindfulness provides a collective community activity with a particular experiential and acceptance-based approach. As such, it may help young people to know themselves better, realize their true capacities, cultivate positive behavioural/internal processes, and build resiliency. Furthermore, it has the potential to promote their sense of safety, psychological wellbeing, social competence, mental health, and academic success (Rawana, Diplock, \& Chan, 2018).

The process of education, from this context, can equip learners with agency and a sense of purpose and build competencies that learners would need for contributing to their own lives and the lives of others (OECD, 2018). Schools, in this regard, are recognized as unique long-term settings 
for fostering students' wellbeing and resilience, and helping them develop as whole people (OECD, 2018; World Health Organization, 1999).

\section{Mindfulness in Schools}

Parallel to the progression of mindfulness-based models for adults, which began in the late 1970s, a surge of initiatives has emerged since the end of the 1990 s relating to the potential benefits of mindfulness in educational settings. Some of these programs mirror the clinical MBSR and MBCT models, albeit with adaptations for children and youth (Felver, Doerner, Jones, Kaye, \& Merrell, 2013; Semple \& Burke, 2019). However, most of the schoolbased programs use a non-clinical orientation, designed to enhance children's wellbeing, social-emotional development, coping strategies, and resilience.

The emerging field, most commonly named mindfulness in education, is accompanied by publications, books, and research initiatives. It encompasses implementations and curricula for school-based students, as well as modules for teachers and educators. The number of related peer-reviewed publications per year rose from 2 in 2002 to 101 in 2017, covering conceptual papers, field-based research, systematic reviews, and meta-analyses assessments (Ergas \& Hadar, 2019).

In the education field, as in clinical practice, mindfulness can fulfil different roles. The functions in clinical practice can be conceptualized along a continuum, from implicit to explicit (Germer, 2005). At the more implicit end of the continuum are the potential benefits for the practitioner, such as enhancing one's humanity, sensitivity, kindness, and presence. Next, in the continuum, is the execution of mindfulness-informed therapy, where numerous mindfulness-based perspectives, dialogues, inquiries, and practices inspire the therapeutic sessions. And at the explicit end of the continuum, specific principles and practices are tailored to the patient, with personalized guidance in how to apply them in life situations (Germer, 2005).

Similarly, the incorporation of mindfulness into education may diversify into several specific formats and functions:

1. The teacher's aspect. This domain involves mindfulness-based trainings for educators, to assist them in self-care and self-leadership. Programs in this domain come to support teachers in cultivating selfawareness, emotional regulation, unconditional presence, self-compassion, and resilience. 
2. The classroom's domain. Programs in this domain instruct teachers to integrate mindfulness-based principles into a class or curriculum and to introduce mindfulness-based practices to children. The nature and structure of each of these programs determine its distinct benefits and outcomes, such as enhancing socio-emotional functioning, strengthening resilience, improving academic success, or developing gratitude and empathy.

3. A whole-school approach. Unlike a classroom-based approach, a wholeschool approach to mindfulness involves full integration of mindfulness in the school curriculum, culture, and climate, an engagement of the teachers, and some incorporation of parents (Kielty, Gilligan, \& Staton, 2017; Sheinman \& Hadar, 2017). The best framework for such an approach is the Health Promoting Schools initiative of the World Health Organization (WHO), a defined, applied, and studied framework (Langford et al., 2014; Stewart-Brown, 2006). This multifaceted, long-term approach to mindfulness seems to offer a more transformative and sustainable model, though a more challenging one.

4. Mindfulness as education. Mindfulness as education, or education through mindfulness, shifts mindfulness from an add-on practice that may support various aims to a pedagogical method and education per se. Mindfulness as education implies a model in which mindfulnessbased pedagogies, principles, and practices are at the core of the teaching and learning process, usually with an emphasis on introspection, selfreflection, experiential knowing, and transformative learning (Ergas \& Hadar, 2019).

\section{Mindfulness and Education's Future Paradigm}

The expansion of mindfulness in education corresponds to global discussions concerning the goals of education and the role of schools. The last decade has seen a growing consensus among educators, researchers, education scholars, policymakers, and the public-at-large about the urgent need for a more comprehensive vision of education. From this perspective, education should be a resource for responding to the global challenges we face, and for creating and applying wise alternatives. As a recent UNESCO's Futures of Educations document states, knowledge and learning are humanity's most significant renewable resources for responding to challenges and for inventing alternatives. Moreover, the document highlights that education should not only 
respond to a changing world but transform lives and the world (UNESCO, 2019).

Preparing children for life, according to these principles, requires an approach that does not focus only on the mastery of academic skills, and supports them in becoming responsible adults (Maynard, Solis, \& Miller, 2015). Respectively, schools are not only places for learning, but settings which promote positive development. Schools can play an essential role in protecting and promoting health, cultivating wellbeing and competencies, and supporting children's ability to cope with life's adversities and challenges (European Network for Mental Health Promotion, 2009).

UNESCO advocated these educational principles in three reports. The 1972 report, Learning to Be: The World of Education Today and Tomorrow, warned of the risks of inequalities and suffering, and emphasized the need for continued expansion of education and lifelong learning (UNESCO, 1972). The 1996 report, The Treasure Within, proposed an integrated model of education based on a four pillars principle: learning to be, learning to know, learning to do, and learning to live together in a lifelong perspective (UNESCO, 1996). More recently, the Rethinking Education: Towards a Global Common Good document reframed the purpose of education, stating that "sustaining and enhancing the dignity, capacity, and welfare of the human person, in relation to others and nature, should be the fundamental purpose of education in the twenty-first century" (UNESCO, 2015, p. 36).

The OECD's (2018) parallel project, Future of Education and Skills 2030, states:

Education has a vital role to play in developing the knowledge, skills, attitudes, and values that enable people to contribute to and benefit from an inclusive and sustainable future. Education [should] equip learners with agency and a sense of purpose, and the competencies they need, to shape their own lives and contribute to the lives of others. (p. 5)

The role of education, as defined in this position paper, is to help every learner develop as a whole person, fulfil his or her potential, and help shape a shared future built on the wellbeing of individuals, communities, and the planet (OECD, 2018).

Accordingly, future schools and curriculums should develop life skills (World Health Organization, 1999) and cultivate competencies like selfawareness, self-regulation, resilience, perspective taking, empathy, gratitude, mindfulness, and leadership (OECD, 2018; Schleicher, 2018). There are challenges in accomplishing these goals, asserts Andreas Schleicher (2018), the director of the OECD education task force, because the development 
of these cognitive, social, and emotional capabilities requires a very different approach to learning and teaching and a different calibre of teachers.

Furthermore, ample evidence-based data shows that children learn best when treated as human beings with social and emotional needs (National Commission on Social, Emotional, and Academic Development, 2019). A growing body of research indicates that academic achievement, social and emotional competence, and physical and mental health are fundamentally and multiply inter-related. The best and most efficient way to foster any of those is to foster all of them (Diamond, 2010).

Social and emotional learning (SEL), in this regard, is the process through which we learn to recognize and manage emotions, care about others, make good decisions, behave ethically and responsibly, develop positive relationships, and reduce negative behaviours (Zins, Bloodworth, Weissberg, \& Walberg, 2007). The need for such a school-based approach is specifically significant for at-risk populations, such as those exposed to adversity, poverty, violence, and divorce (Jennings, Lantieri, \& Roeser, 2012).

Recent recommendations from the U.S. National Commission on Social, Emotional, and Academic Development (2019) boldly states:

It is a mistake to view social and emotional learning as a "soft" approach to education. An emphasis on these capacities is not the sacrifice of rigor; it is a source of rigor. Educating the whole learner cannot be reduced to a simple set of policies or proposals. It is, instead, a mindset that should inform the entire educational enterprise. (p. 7)

More than two decades of research across a wide range of disciplinespsychology, social science, and brain science-demonstrates that learning depends on deep connections across a variety of skills, attitudes, and traits. These generally fall into three broad categories: (1) competencies and skills, (2) attitudes, beliefs, and mindsets, and (3) character and values (Aspen Institute National Commission on Social, Emotional, and Academic Development, 2019).

Mindfulness in education is strongly linked to many of the above themes and objectives. Mindfulness-based principles, practices, and pedagogies may provide unique modus operandi for building up children's dispositions, competencies, and healthy development. 


\section{Mindfulness-Based Principles with Children and Youth}

There are significant differences between the various school-based mindfulness initiatives (with children and adolescents) and the clinical models designed for adults. The most notable distinctions are the age (children and youth vs. adults) and the context (schools vs. clinics). Accordingly, schoolbased mindfulness must address developmental issues, children's inner needs, attention capacities, and cognitive and metacognitive abilities, as well as motivation theories, school/classroom contexts, and other factors. There is a general agreement that adaptations of mindfulness for children call for shorter sessions, inclusions of movement and imagery, optional playfulness, stories, songs, and games, and the use of group inquiries and personal diaries (Semple \& Lee, 2014). Unlike the structured mindfulness-based models for adults, many education-based versions leave more space for improvisations and creative innovations (see Table 24.1).

Other parameters, relevant in working with children and youth include:

- Whole-child perspectives. A whole-child approach to education focuses attention on the emotional, social, mental, physical, and cognitive development of students. At its core, the approach views the purpose of schooling as developing future citizens and providing the basis for children to fulfil their potential (Diamond, 2010; Slade \& Griffith, 2013).

- Children's basic needs. Mindfulness-based programs should resonate with themes of child development and with students' developmental needs. Olness and Kohen (1996) postulate that working with children requires awareness of each child's urge for mastery, positive experiences, social interaction, wellness, and the inner world of imagination (Olness \& Kohen, 1996). Self-motivation theory (Ryan \& Deci, 2000) postulates three innate psychological needs - competence, autonomy, and relatednesswhich, when satisfied, yield enhanced self-motivation, mental health, and wellbeing.

- Age adaptation. When applying mindfulness with children and youth, it is essential to execute age-appropriate principles. Each program's component, be it a guided experience, explanation, inquiry, or psychoeducation, needs to modify and adapt according to the relevant age. In essence, various programs tend to use $2-3$ age adapted versions.

- Embodied teaching. The quality of any mindfulness in education program depends on the delivery agent-the teacher/facilitator. A core component of any program is, therefore, not only the instructor's understanding of 
Table 24.1 Mindfulness for adults vs. mindfulness with children and youth

\begin{tabular}{|c|c|c|}
\hline & $\begin{array}{l}\text { Mindfulness-based } \\
\text { interventions with adults }\end{array}$ & $\begin{array}{l}\text { Mindfulness in } \\
\text { education with } \\
\text { children and youth }\end{array}$ \\
\hline Target population & Adult patients & Children and youth \\
\hline Context & $\begin{array}{l}\text { Hospitals, clinics, and } \\
\text { therapeutic institutes }\end{array}$ & $\begin{array}{l}\text { Schools, classrooms, } \\
\text { and youth programs }\end{array}$ \\
\hline Main models & MBSR, MBCT, MSC & $\begin{array}{l}\text { Various models and } \\
\text { versions }\end{array}$ \\
\hline Special adaptations & $\begin{array}{l}\text { Adaptations according to } \\
\text { medical or psychological } \\
\text { themes }\end{array}$ & $\begin{array}{l}\text { Adaptations according } \\
\text { to age, culture, } \\
\text { education contexts, } \\
\text { and special needs }\end{array}$ \\
\hline Moderated by & Qualified facilitators & $\begin{array}{l}\text { Professional facilitators } \\
\text { or trained school } \\
\text { teachers }\end{array}$ \\
\hline Program's Duration & 8-week & $\begin{array}{l}\text { Ranging from a few } \\
\text { sessions to an } \\
\text { ongoing long-term } \\
\text { integration }\end{array}$ \\
\hline Length of each session & 2.5 hours, once a week & $\begin{array}{l}\text { From a few minutes } \\
\text { (daily) to } 45 \text { minutes } \\
\text { (a week), or both }\end{array}$ \\
\hline Length of practices & 15-45 minutes & 3-15 minutes \\
\hline Home practice & Expected and required & $\begin{array}{l}\text { Suggested, not } \\
\text { demanded }\end{array}$ \\
\hline $\begin{array}{l}\text { Integrations with other } \\
\text { modalities }\end{array}$ & $\begin{array}{l}\text { Integrations with cognitive } \\
\text { modalities or mindful } \\
\text { yoga }\end{array}$ & $\begin{array}{l}\text { Integrations with yoga, } \\
\text { expressive art, council } \\
\text { circles, music, positive } \\
\text { psychology, } \\
\text { social-emotional } \\
\text { learning, imagery, } \\
\text { compassion-based } \\
\text { themes, and more }\end{array}$ \\
\hline Expected outcomes & $\begin{array}{l}\text { Symptom reduction. } \\
\text { Psychological or } \\
\text { physiological } \\
\text { clinical-based outcomes }\end{array}$ & $\begin{array}{l}\text { Cultivation of } \\
\text { competencies and } \\
\text { enhancement of } \\
\text { wellbeing. Variety of } \\
\text { developmental, } \\
\text { emotional, mental, } \\
\text { behavioural, and } \\
\text { cognitive outcomes, } \\
\text { with potential } \\
\text { applications and } \\
\text { contribution in school } \\
\text { contexts and } \\
\text { out-of-school life }\end{array}$ \\
\hline
\end{tabular}


mindfulness but his or her ability to role model the principles, embody a non-reactive mindset, and demonstrate a "being-mode" and a "beginner's mind" attitudes (Broderick et al., 2019).

- Repetitiveness. We can enhance children's disposition to learn and apply the practices by repetitiveness, built into the design of the sessions, classes, or curriculums (Semple \& Lee, 2014).

- Variety. Variety increases children's interest and balances the repetitiveness. We can create it by using different versions for a specific practice (e.g., using different versions of a breath awareness practice), by inserting several short exercises within a more extended classroom session, by creating gradual challenges (e.g., from two-minute mindful silence to five-minute), or by leaving an expressive-creative time after a meditative practice time (Semple \& Lee, 2014).

- Inquiry and expression. Creating a safe space for discussing and sharing (in small groups or a whole-class circle) can be introduced to sessions to enhance children's reflection, cognition, sense of connectedness, listening skills, and insight potential (Semple \& Lee, 2014). Written or creative (non-verbal) expression, as in a mindful journal, are other helpful aids in the learning process.

- The intensity or dose-response. A few minutes of a mindful practice, sporadically introduced, will leave a smaller imprint compared to a 45minute class, delivered once a week for a whole year. Factors influencing the "dose-response" are the frequency of the sessions (e.g., once, twice, or five times a week), the number of classes in a given program (or per year), the length of each class (e.g., 15 minute or 45 minute), the duration of each experiential session (a few minute script or a longer one), the balance between explanation, experience, expression, and inquiry, and the repetitiveness of each experience (e.g., Greenberg \& Harris, 2012; Schonert-Reichl \& Roeser, 2016).

The above themes and parameters overlap with the positive-activity model, defined and discussed in positive psychology (Lyubomirsky \& Layous, 2013). The model addresses activity-based features and person-based features that influence an improvement in wellbeing. According to the model, various elements of the activity (e.g., dosage, variety) and characteristics of the person (e.g., needs, motivation, effort) influence the expected improvement in wellbeing. Thus, an optimal person-activity fit (i.e., the overlap between activity and personal features) predicts an increase in wellbeing (Lyubomirsky \& Layous, 2013). 


\section{Mindfulness in Education Around the World}

The worldwide implementation of mindfulness-based programs in schools is escalating, and the number of publications on the topic is rapidly swelling (Schonert-Reichl \& Roeser, 2016). As seen in the literature and publications around the world, mindfulness in education can take many forms, framing styles, components, and integrations (Ergas \& Hadar, 2019; Semple et al., 2017; Zenner et al., 2014). The following section presents a sample of mindfulness in education programs from around the world (summarized in Table 24.2).

\section{Australia}

Two Australian-made models can be found in various schools around the country: Meditation Capsules and Smiling Mind. Some mixed versions of Mindfulness in Schools Project (U.K.), MindUp (U.S.), and Mindful Schools (U.S.) are also present. Most initiatives are executed at the classroom level and are led by schoolteachers who are inspired to incorporate mindfulness within education training.

The Meditation Capsules model (Etty-Leal, 2010) integrates a range of meditation-based themes and techniques, designed to enhance wellbeing, compassion, and general academic performance (Ager, Albrecht, \& Cohen, 2015). Topics include mindfulness and self-awareness, understanding stress, body and breath awareness, observation of thoughts, mindfulness and the senses, communication dynamics, humour, creativity, and stillness. The model is integrated into a whole-school approach of positive education, as applied by the Geelong Grammar School, Australian institute of positive education (Norrish, 2015).

Smiling Mind is a web and app-based program, developed by psychologists and educators. It was launched in 2012 to support the wellbeing of students and teachers, and to help them with the pressure, stress, and challenges of daily life (Smiling Mind, 2017). The model is organized in four ageappropriate versions (ages 7-9, 10-12, 13-15, 16-18), and offers a variety of lesson plans, activities, and guided sessions, adjusted for children, youth, and adults (Bailey et al., 2018; Smiling Mind, 2017). 
Table 24.2 Mindfulness in schools initiatives around the world

\begin{tabular}{|c|c|c|c|c|c|}
\hline Country & Program & Year & Unique themes & Implementation & Facilitated by \\
\hline Australia & $\begin{array}{l}\text { Meditation } \\
\text { Capsules }\end{array}$ & 2000 & $\begin{array}{l}\text { Integration of } \\
\text { expressive arts } \\
\text { and group } \\
\text { dialogues }\end{array}$ & $\begin{array}{l}\text { Depended on } \\
\text { teachers' } \\
\text { implementation } \\
\text { decisions }\end{array}$ & $\begin{array}{l}\text { School } \\
\text { teachers }\end{array}$ \\
\hline Australia & $\begin{array}{l}\text { Smiling } \\
\text { Mind }\end{array}$ & 2012 & $\begin{array}{l}\text { A web-based and } \\
\text { app-based } \\
\text { initiative }\end{array}$ & $\begin{array}{l}\text { Depended on } \\
\text { teachers' } \\
\text { implementation } \\
\text { decisions }\end{array}$ & $\begin{array}{l}\text { Web-based } \\
\text { recordings }\end{array}$ \\
\hline Bhutan & $\begin{array}{l}\text { GNH in } \\
\text { Education }\end{array}$ & 2010 & $\begin{array}{l}\text { Whole country } \\
\text { implementation; } \\
\text { part of the } \\
\text { national Gross } \\
\text { National } \\
\text { Happiness (GNH) } \\
\text { policy }\end{array}$ & $\begin{array}{l}\text { Depended on } \\
\text { teachers' } \\
\text { implementation } \\
\text { decisions }\end{array}$ & $\begin{array}{l}\text { School } \\
\text { teachers, } \\
\text { trained by } \\
\text { school } \\
\text { principals }\end{array}$ \\
\hline Israel & $\begin{array}{l}\text { Sfat } \\
\text { Hakeshev }\end{array}$ & 1998 & $\begin{array}{l}\text { Whole-School- } \\
\text { based model; } \\
\text { integration with } \\
\text { each grade's } \\
\text { annual curriculum }\end{array}$ & $\begin{array}{l}\text { Weekly classes } \\
\text { for a whole } \\
\text { year, year by } \\
\text { year }\end{array}$ & $\begin{array}{l}\text { Professional } \\
\text { facilitators, } \\
\text { who } \\
\text { become } \\
\text { part of the } \\
\text { school's } \\
\text { faculty }\end{array}$ \\
\hline $\begin{array}{l}\text { New } \\
\text { Zealand }\end{array}$ & PBS & 2012 & $\begin{array}{l}\text { Aligned with } \\
\text { Maori-based } \\
\text { perspectives and } \\
\text { values }\end{array}$ & $\begin{array}{l}\text { Eight weekly } \\
\text { lessons, and } \\
\text { then ongoing } \\
\text { implementation }\end{array}$ & $\begin{array}{l}\text { School } \\
\text { teachers }\end{array}$ \\
\hline UK &.$b$ & 2009 & $\begin{array}{l}\text { Under a major } \\
\text { research project } \\
\text { (MYRIAD) }\end{array}$ & $\begin{array}{l}\text { Ten weekly } \\
\text { structured } \\
\text { classes }\end{array}$ & $\begin{array}{l}\text { School } \\
\text { teachers }\end{array}$ \\
\hline USA & MindUp & 2005 & $\begin{array}{l}\text { Neuroscience and } \\
\text { SEL-based } \\
\text { curriculum }\end{array}$ & $\begin{array}{l}15 \text { structured } \\
\text { sessions }\end{array}$ & $\begin{array}{l}\text { School } \\
\text { teachers }\end{array}$ \\
\hline USA & L2B & 2002 & $\begin{array}{l}\text { Adaptation of } \\
\text { MBSR to } \\
\text { adolescents }\end{array}$ & $\begin{array}{c}6,12, \text { or } 18 \\
\text { sessions }\end{array}$ & $\begin{array}{l}\text { Trained } \\
\text { facilitators } \\
\text { or trained } \\
\text { teachers }\end{array}$ \\
\hline USA & $\begin{array}{l}\text { Mindful } \\
\text { School }\end{array}$ & 2007 & $\begin{array}{l}\text { Integrative training } \\
\text { for teachers }\end{array}$ & $\begin{array}{l}25-30 \text { sessions, } \\
15-\text { minutes } \\
\text { each, } 2-3 \\
\text { times a week }\end{array}$ & $\begin{array}{l}\text { Mindfulness } \\
\text { experts and } \\
\text { school } \\
\text { teachers }\end{array}$ \\
\hline
\end{tabular}

\section{Bhutan}

Mindfulness in education in Bhutan is part of the nationwide implementation of Gross National Happiness (GNH), the country's developmental philosophy. According to GNH principles, all government policies match four 
pillars: sustainable socio-economic development, preservation and promotion of culture, conservation of the environment, and good governance (Hayward, Pannozzo, \& Colman, 2009; Hayward \& Colman, 2010).

The country's Educating for Gross National Happiness initiative started in 2010 (Drupka \& Brien, 2013). Training and a workbook manual were introduced to all Bhutan's school principals, urging them to train their teachers. All schools were requested to infuse values and principles of gross national happiness into their curricular programs and extra-curricular activities (Sherab et al., 2014).

The GNH in Education model adopted mindfulness as an essential element in developing students as GNH graduates (Bhutan's Ministry of Education, 2013). The model's manual incorporates a module on meditation and mind training and offers verbatims for seven guided mindfulness-based practices of a few minutes each. Teachers are instructed to introduce these practices in whole-school assemblies, before class, before or after sports competitions, or at the beginning or end of the day. Although Bhutan is a Buddhist country, the guided scripts emphasize secular mindfulness, designed to enhance stress relief, support positive emotions, and cultivate contemplative and reflective learning (Bhutan's Ministry of Education, 2013).

\section{Israel}

Israel's first mindfulness in education initiative (Sfat Hakeshev, The Mindful Language) started in 1998 as a whole-school project (primary school, age 612 years), echoing the Health Promoting School (HPS) principles of the WHO (n.d.; see also Sheinman \& Hadar, 2017). The main goals were to enhance children's self-awareness, improve self-efficacy and resilience, develop socialemotional skills, prevent risk behaviours, and improve learning potential.

The model introduces mindfulness-based sessions as an integral part of each class's curriculum (primary school, age 6-12), presented once a week for a whole year, year after year. Each session (45 minutes) integrates mindfulness-based practices, yoga-based movements and postures, specific imagery-based processes, inquiry time, and a personal journal. Sessions are taught by experienced mindfulness instructors and take place in a "mindfulness room", empty of chairs and desks. The "dose" is enhanced by the homeroom teachers, who weave short mindfulness-based sessions into their classes.

Unlike most mindfulness in education programs around the world, the Sfat Hakeshev model offers an ongoing six years process (from age 6-12), with integrations of mindfulness into a school's curriculum, culture, and climate. 
The extended duration of the program allows the gradual learning of competencies, insights, and coping strategies (Semple et al., 2017). Although only a few schools maintain the program, the long-term sustainability creates a unique contribution to children's coping strategies and their responses to everyday challenges (Sheinman, Hadar, Gafni, \& Milman, 2018).

At least two additional models are currently being applied and researched: The Call to Care program (Tarrasch, Berger, \& Grossman, 2020), and the Purple School initiative (a three years project applying a whole-school approach; Ergas \& Avisar, in press). Further, many colleges of education in the country offer mindfulness-based classes as an elective or required course.

\section{New Zealand}

The leading mindfulness in schools' program in New Zealand is the Pause, Breath, Smile (PBS) initiative, launched in 2012. Work to date includes the development, application, dissemination, research, and refinement of the model. The program is sensitive to curriculum guidelines of New Zealand's Ministry of Education, as well as to specific principles related to New Zealand's indigenous Maori population (Bernay, Graham, Devcich, Rix, \& Rubie-Davies, 2016).

The program consists of a structured eight one-hour weekly classes, taught by trained schoolteachers. After the eight weeks, teachers are encouraged and supported to continue weaving the practices in their classes throughout the school year. The practices include mindfulness of breathing, mindful movements, body scan, mindful listening, mindful eating, a loving-kindness practice called "kind heart, happy heart", and a mindful breathing practice focused on fostering a sense of connection to the natural world (Bernay et al., 2016).

The programs' indigenous principles correspond with Te Whare Tapa Wha, "The House with Four Walls", a holistic wellbeing Maori concept. Children are invited to reflect on four domains or "cornerstones" of healthphysical wellbeing (taha tinana), mental and emotional wellbeing (taha hinengaro), family and social wellbeing (taha whanau), and spiritual wellbeing (taha wairua) - and to apply principles of mindfulness within each of these domains (Devcich, Rix, Bernay, \& Graham, 2017). 


\section{U.K.}

The most established mindfulness in education initiative in the U.K. is the Mindfulness in Schools Project (MiSP), launched in 2009 as a national not-forprofit charity for young people and schools. The initiative's model includes the ". $b$ " program ("dot-b", standing for "stop and be"), designed for 11-18year-olds, and the "Paws b" program, developed in 2013 for 7-11-year old.

The implementation is based on a syllabus of ten weekly 45-minute structured sessions (12 short lessons in Paws b), geared to fit into the school curriculum, and taught by classroom teachers trained to deliver the program. Each session focuses on a distinct theme and skill and integrates didactic presentation, film clips and animations, guided practice, and interactive exploration and inquiry. The curriculum synthesizes MBSR and MBCT principles with appropriate age adaptations (Kuyken et al., 2013). Themes include paying attention, taming the mind, working with worry, being in the now, befriending the difficult, and taking in the good. Short experiential practices introduce mindfulness of breath and body, the passing nature of thoughts, mindful eating and walking, and ways for dealing with stress. (See https://mindfulnessinschools.org/teach-dot-b/dot-b-curriculum.)

The program is currently part of an extensive multi-year randomized controlled trial project, called My Resilience in Adolescence (MYRIAD), conducted in over 80 schools. The project aims to assess whether mindfulness training in schools can shift young adults away from psychopathology and towards improved mental health, resilience, and wellbeing (Kuyken et al., 2017).

\section{U.S.}

Mindfulness in education in the U.S. is diverse and abounds with initiatives, programs, and research projects. For this chapter, we chose three initiatives: the MindUp curriculum for elementary school children, the Learning to BREATHE curriculum for adolescents, and the Mindful Schools teachers training model.

MindUP. The Mind $U_{p}$ program is a classroom-based curriculum for elementary school children, created in 2005 by the Hawn Foundation. The program includes 15 lessons of thirty minutes each, with three ageappropriate curriculums. The teaching units are informed by research findings from cognitive neuroscience, social and emotional learning, positive psychology, and mindfulness training. The program aims to foster children's 
social-emotional wellbeing, prosocial behaviour, and academic success (Hawn Foundation, 2011).

The teaching units include information on the brain structure and function, to help students develop an understanding of the brain's role in emotions, behaviour, decision-making, and learning. Topics encompass attention to the senses (i.e., mindful listening, seeing, smelling, tasting), and mindful movement. Other units focus on attitude, perspective taking, optimism, gratitude, kindness, and taking action (Maloney, Lawlor, SchonertReichl, \& Whitehead, 2016). A few minutes of a mindful breath awareness is integral to the lesson plans, to help students focus, settle, and calm down. Teachers are encouraged to present the lessons at regular intervals throughout the typical 32-week school year and to integrate the short breath awareness practice within their ongoing teaching (Hawn Foundation, 2011).

Learning to BREATHE. Learning to BREATHE (L2B) is a mindfulness-based curriculum for adolescents, created for classroom settings. The curriculum intends to strengthen attention and emotion regulation, cultivate wholesome emotions like gratitude and compassion, expand the repertoire of stress management skills, and help participants integrate mindfulness into daily life (Broderick \& Frank, 2014).

The model consists of six lessons of 45-minute each, with six core themes: (1) body awareness; (2) understanding and working with thoughts; (3) understanding and working with feelings; (4) integrating awareness of thoughts, feelings, and bodily sensations; (5) reducing harmful self-judgements; and (6) integrating mindful awareness into daily life (Metz et al., 2013). Each lesson includes a short introduction of the topic, several activities for group participation, discussion to engage students in the lesson, and an opportunity for in-class mindfulness meditation practice (Broderick, 2013).

The Mindful School initiative. A prevalent mindfulness in education model in the U.S. is the Mindful Schools initiative, established in 2007. A central aim of the model is to build attention, self-regulation, and empathy (Mindful Schools, 2015). Initially, the model relied on facilitation executed by the program's trained mindfulness practitioners, but now concentrates on training educators in developing their mindfulness practice, and in adapting mindfulness to their students (Semple et al., 2017).

The training offers two age-adapted curricula: a 30-module version for age $5-12$, and a 25 -module version for age 12-17. The lessons are structured as a 15-minute increment, delivered two to three times per week. Topics include mindful breath and body exercises, mindfulness in different sensory modes (e.g., listening or eating), mindfulness of thoughts and emotions, and activities to promote gratitude, generosity, and compassion. Discussions about 
ways that students might incorporate mindfulness into their daily lives are part of each lesson. Student workbooks are available to support optional 5-minute journaling at the end of each lesson.

\section{Mapping the Themes}

The programs described above, as well as publications, books, reviews, and meta-analyses, reveal a highly heterogeneous composition of methods, implementation principles, age populations, and foci. The diversity of programs, the pilot-character of many studies, and challenges in finding adequate scales (reliable assessment tools) make an accurate impression of effectiveness challenging to get. Variations in programs' structure, duration, chosen practices, and expected results challenge the ability to make conclusions regarding best practices or evidence-based outcomes (McKeering \& Hwang, 2019).

A recent thorough mapping of the field assessed 447 peer-reviewed papers published between 2002 and 2017 and identified common recurrent themes (Ergas \& Hadar, 2019). The assessment found six different perspectives from which academic papers cover the field: explaining the field, justifying the field, demonstrating implementation principles, studying mindfulnessbased effects, analyses and reviews, and critical analysis of the field. In the context of the framing of mindfulness-based programs in schools, the following categories were isolated: (1) wellbeing and mind-body health, (2) social-emotional learning, (3) self-knowing and transformative learning, (4) academic performance and cognitive functions, (5) behaviour and conduct, and (6) spirituality. There were a few other domains relating to teaching, learning, critical pedagogy, and higher education.

Many experts in the field agree on the need for more high-quality quantitative and qualitative research, needed to shed light on better ways of assessing outcomes with children, and means for evaluating fidelity of programs' implementation. As already observed in the field of social and emotional learning, reliable means of assessing fidelity of program implementation can strengthen research, support instructor training, and contribute to program improvement (Broderick et al., 2019).

At present, there are no standardized instruments for assessing the implementation quality of mindfulness in education programs. Broderick et al. (2019) pointed out that such measures require attention to two major domains: the adherence to an existing given program (e.g., explanations and practices), and the quality or process of the implementation itself (e.g., how it was explained, guided, and taught). The cultivation of mindfulness in 
schools, akin to teaching adults, requires adherence to the program model, as well as an embodiment of the attitudinal foundations of mindfulness (Kabat-Zinn, 1990).

The broad range of versions and the lack of a standardized protocol may represent the strength of the mindfulness in education field, not a shortfall. As expressed by Burnett, founder of the U.K. MiSP program, the multiplicity of options can demonstrate the field's sense of possibilities, presenting a spectrum of potential applications of these perspectives and practices, when applied in educational contexts (Burnett, 2011). Mindfulness in education practices can exist within a range of possibilities, from functional ones (enhancing calmness, reducing stress, improving sleep) to the therapeutic (alleviating restlessness, anger, anxiety), to wellbeing (increasing selfawareness, resilience, wellbeing), through to the more spiritual (introducing mystery, wonder, meaning).

\section{The Benefits for Children and Youth}

Despite the heterogeneous nature of the mindfulness in education field, the positive findings across many studies, examining different models, in different countries, and with diverse age groups, appear promising. The evidence suggests that well-conducted programs appear to be welcomed by students and teachers, have positive impacts on the psychological, mental, and social health of the young, improve the wellbeing of children and adolescents, and reduce the overall burden of health spending by focusing on preventive interventions (Semple \& Burke, 2019; Weare, 2019). Beyond that, the teachers' involvement with mindfulness can increase their sense of wellbeing and selfefficacy, contributing to a prosocial classroom and positive student outcomes (Jennings et al., 2012).

As evident through numerous studies, publications, and meta-analysis, school-based mindfulness programs may have positive effects on a variety of measures and outcomes, across multiple age levels:

- Reduces stress and depressive symptoms (Felver et al., 2016; Kuyken et al., 2013; Zenner et al., 2014).

- Promotes positive mental health (Schonert-Reichl \& Roeser, 2016).

- Improves psychological wellbeing (Huppert \& Johnson, 2010; Kuyken et al., 2013).

- Supports psychosocial wellbeing (Felver et al., 2016).

- Supports social-emotional learning (Schonert-Reichl et al., 2015). 
- Boost mindfulness-based coping strategies (Sheinman et al., 2018).

- Enhance resilience (Felver et al., 2019).

- Increases positive affect measures, such as a person's sense of happiness and optimism (Sampaio de Carvalho et al., 2017).

- Improves executive functioning (Janz, Dawe, \& Wyllie, 2019).

- Impacts aspects of cognition (Dunning et al., 2019; Klingbeil et al., 2017; Maynard et al., 2015).

Although the accumulated findings on the benefits of school-based mindfulness are significant, none of the studies conducted between-programs comparisons, such as comparing PBS to MiSP, or compared outcomes of a long-term plan to a short-term one. There are also no comparative data on the perspective of students, regarding their experiences, insights, or skills acquisition.

Some distinct programs may serve as an effective strategy for specific targeted outcomes, such as aggressive and problematic behaviours (Felver et al., 2013; Singh et al., 2007), executive functioning skills (Parker et al., 2014), and reduction in depressive symptoms (Bluth et al., 2016). Further, empirical research has demonstrated that school-based mindfulness is generally a safe and effective intervention modality that supports psychosocial wellbeing (Felver et al., 2016).

Mindfulness-based programs are more effective when taught by teachers who understand the principles from within. Each teaching thus becomes an opportunity to embody and generate the particular qualities that mindfulness develops, such as attentiveness, kindness, open-mindedness, curiosity, empathy, compassion, acceptance, and patience. In fact, for teachers, these skills and attitudes are essential for any interaction with young people.

As the field of mindfulness in education evolved, the role of teachers and their influence on outcomes became more explicit. Accordingly, specific mindfulness-based trainings for educators were devised and examined.

\section{Mindfulness for Teachers}

Teachers play an essential role in providing the learning opportunities that influence and shape the character and wellbeing of children and youth (NSW Government, 2015). Considered as the most important in-school factor, teachers contribute to students' learning, personal development, and flourishing (Rivkin, Hanushek, \& Kain, 2005). Teaching, however, is a complex and demanding practice, usually loaded with stress, emotional challenges, job 
dissatisfaction, and burnout, potentially resulting in teachers' poor mental health and reduced wellbeing outcomes (Beltman \& Poulton, 2019; Lomas, Medina, Ivtzan, Rupprecht, \& Eiroa-Orosa, 2017; Zarate, Maggin, \& Passmore, 2019).

Concurrent with the school-based initiatives around the world, and the growing preference for facilitation by school's teachers (versus led by trained mindfulness practitioners), various mindfulness-based programs for teachers are evolved and researched (e.g., Beshai, McAlpine, Weare, \& Kuyken, 2016; Crain, Schonert-Reichl, \& Roeser, 2017; Harris, Jennings, Katz, Abenavoli, \& Greenberg, 2016; Jennings et al., 2019; Schussler et al., 2018). Accordingly, there is a marked increase in peer-review publications related to mindfulness-based programs for teachers (Ergas \& Hadar, 2019).

Generally speaking, two categories of mindfulness-based programs for teachers are prevalent. In the first are programs designated to support teachers' emotional regulation, self-compassion, and wellbeing, in their role as teachers. The second relates to programs designed to train teachers in teaching specific mindfulness in education initiatives. In some programs, the training integrates the two into one long-term gradual learning process, i.e., Presence, Awareness, and Self-Compassion in Schools (PAS) in Austria ${ }^{1}$ or the Purple School Project in Israel. ${ }^{2}$

Both categories acknowledge teachers' stress, emotional challenges and burnout, and seek to improve their coping strategies, resilience, and wellbeing. Some of these initiatives focus on in-service teachers (e.g., Harris et al., 2016), while others focus on pre-service teachers (e.g., Hirshberg, Flook, Enright, \& Davidson, 2020). The ultimate aims of the programs are usually dual: to enhance teachers' wellbeing and mental health (Harris et al., 2016), and to enable them to transfer gained skills into their classroom presence and class management (Hirshberg et al., 2020; Jennings \& Greenberg, 2009).

Weare (2014) summarized various contributions of mindfulness-based programs for teachers, collected mostly by self-report methodologies:

- Reduction in occupational stress and burnout and increase in coping skills.

- Better mental health and less distress, anxiety, and depression tendencies.

- Greater wellbeing, and enhanced life satisfaction, self-efficacy, and selfconfidence.

- Increased kindness, empathy, and compassion to others.

- Better physical health and fewer reported health-related symptoms.

\footnotetext{
${ }^{1}$ https://achtsamkeit.univie.ac.at/en/presence-awareness-and-self-compassion-in-schools-pas.

2 https://www.mop.education/\%D7\%91\%D7\%99\%D7\%AA-\%D7\%A1\%D7\%A4\%D7\%A8-\%D7\% $\mathrm{A} 1 \% \mathrm{D} 7 \% 92 \% \mathrm{D} 7 \% 95 \% \mathrm{D} 7 \% 9 \mathrm{C}$.
} 
- Increased cognitive performance, including decision-making and responseability.

- Enhanced job performance, with better classroom management and attentiveness to students.

Three meta-analysis studies (Klingbeil \& Renshaw, 2018; Lomas et al., 2017; Zarate et al., 2019) assessed the impacts of mindfulness-based programs on educators' wellbeing. The analyses revealed a wide range of delivery modes, joined by a variety of "satellite" components (e.g., yoga, imagery, breathwork, mental exercises, discussions) in varied proportions. Interventions lasted from as little as three weeks up to 16 weeks, and overall intervention time ranged from 4.5 to 42 hours (Zarate et al., 2019). The results demonstrate beneficial impacts upon several metrics of mental health and emotional wellbeing, including decrease stress, anxiety, depression, and burnout (Zarate et al., 2019) and enhanced wellbeing, emotional regulation, and life satisfaction (Lomas et al., 2017). Most experts agree that more quality research and defined standards are required (see Emerson et al., 2017, Emerson, de Diaz, Sherwood, Waters, \& Farrell, 2020).

The expansion of mindfulness in education programs around the world led to various training models aimed at guiding, assisting, or certifying teachers in guiding children. Each program-specific training typically relates to a distinct curriculum, such as the PBS curriculum in New Zealand, the MiSP curriculum in the U.K., or the L2B in the U.S. The training provides a cognitive and experiential understanding of the relevant curriculum and guidelines related to teaching it.

Personal practice is a vital ingredient, especially with mindfulness-based programs, in which the success of the delivery depends on the interior condition of the teachers. There is a consensus among experts about the importance for teachers to acquaint themselves with the experiential non-cognitive qualities (e.g., patience, acceptance, non-striving, kindness) embedded in mindfulness-based practices (Albrecht, 2018). Moreover, mindfulness-based practices may reduce teachers' self-centredness (Berkovich-Ohana, Jennings, \& Lavy, 2019), and promote awareness, reflection, and attentiveness (Roeser, Skinner, Beers, \& Jennings, 2012). These may enable improved socialemotional competence, attunement to students, and a positive classroom climate (Berkovich-Ohana et al., 2019; Roeser et al. 2012). 


\section{Mindfulness and Positive Education}

Mindfulness and positive psychology, in their philosophy, assumptions, and intentions, share several common themes, a fact that provides a fertile ground for in-depth dialogue and mutual learning. There are emergent discussions concerning the potential integration of these two fields, albeit mostly regarding adults. Recent attempts have already started to explore possible ways to weave and integrate mindfulness and positive psychology among school-aged children. Still, the evidence-based literature examining the synergy between the two is rather scanty.

As Ivtzan and Lomas (2016) reported, relating to adult populations, research has indicated that mindfulness enhances both hedonic and eudemonic wellbeing. Furthermore, the synergy between character strength (as defined by positive psychology) and mindfulness, and the potential integration between the two, have been described and discussed (Niemiec, 2013). Investigations of programs with adults have found that mindfulness-based outcomes correlated with higher levels of self-esteem, satisfaction with life, psychological flexibility, happiness, positive affect, and optimism (Shapiro, de Sousa, \& Jazaieri, 2016).

Both mindfulness in education and positive education agree that twenty-first-century schooling should enhance social-emotional competencies, psychological health, wellbeing, and resilience. The two approaches seem to differ in the methodologies offered to achieve these desired outcomes. Integrating both perspectives, supported by their accumulative science and practice, can enhance our understanding and application of each, and potentiate both.

Former programs that included mindfulness in positive education executed the integration in varying degrees and styles. For instance, in one initiative in Bhutan, the ratio between the mindfulness-based sessions and the life skills themes in the curriculum was 1:10, and the typical timespan of each mindfulness-based practice was only a few minutes (Adler, 2016). Another positive education initiative in Spain, which studied the Happy Classroom Program, combined mindfulness-based themes with character strength themes on a 1:1 ratio (Lombas et al., 2019). However, the average timespan of each mindfulness-based session, implemented twice a week during the 18 -week project, was less than 4 minutes each. From a mindfulness in education perspective, and the "dose-response" principle, both initiatives represent a low dose and a low-intensity protocol.

In conceptualizing collaboration and integration between positive education and mindfulness in education, various themes seem to stand out: 
- Further explorations can determine and uncover how to best integrate the two systems and generate a more inclusive, holistic, and systematic model.

- Each discipline has its tradition, perspectives, definitions, and terminologies, and there is a lack of a shared language. There is a need for more dialogue and agreements on taxonomy, measures and research methods, and their translation into practice.

- Character strength and developmental assets principles, unique to positive psychology, are lacking in the mindfulness in education pedagogies. Further work is needed to explore how mindfulness, character strength, and assets can work together or enhance each other, for the benefit of children or teachers.

- Further research on mindfulness-based practices can optimize its application for positive youth development.

- The experiential practices of mindfulness, adapted to youth, offer unique "learning from within" methods for positive psychology. Current outcomes with children already demonstrate the power of these practices to enhance self-awareness, serenity, self-regulation, self-compassion, kindness, coping skills, and resilience.

- Mindfulness-based practices can enhance children's coping strategies, thus complementing the coping skills attained through positive education programs.

- The application of movement-based practices, prevalent in mindfulness in education, may serve positive education pedagogies.

- Mindfulness-based practices, coupled with an inquiry, reflection, and dialogue, create a contemplative pedagogy that deepens insights and selfdiscovery. The contemplative methods can complement the pedagogies of positive psychology and positive education.

- Comparing whole-school models, which already exist in both systems, can amplify insights on implementation and sustainability.

- Creating a database of what did not work well in each field may finetune our approaches and help us in cultivating wellbeing, resilience, and character.

Transforming children, teachers, schools, or education systems is complex and dynamic, and therefore requires joint efforts from different fields. We envision collaborative cooperation between mindfulness in education and positive education, leading to integrative, holistic, creative, and science-based models. We believe that integrating the two perspectives, in research and practice, can contribute to a whole, which is bigger than the sum of the parts, in a way that is applicable, effective, transformative, and sustainable. 


\section{Conclusions and Future Directions}

Educational leaders, policymakers, teachers, and students worldwide are excited about the growing recognition that we must support the whole learner and ensure children receive the ingredients they need to evolve and thrive. Schools, in this context, provide the most effective and efficient way to reach young people, as well as educators, and to cultivate their life skills and wellbeing competencies. Mindfulness in education offers unique pedagogies, principles, and practices which resonate with these visions and missions.

This chapter focused on critical issues of mindfulness-based practices in the education field: the evolution and proliferation of mindfulness in educational contexts, the place of mindfulness-based pedagogies within education for wellbeing, prototypes of educational models and initiatives from around the world, various outcomes and insights gained from mindfulness-based methods for both students and teachers, and potential meeting points between mindfulness in education and positive education as a foundation for integrative dialogue and collaboration.

The field of mindfulness in education encompasses a broad diversity of models, formats, and functions. Empirical research examining the effectiveness of such programs has increased exponentially, although not always keeping up with the escalation of classrooms and school-based activities. Although there is a need for more maturation in the field, the overall results, accumulated from many countries, are significant and promising. In light of all that has been done, explored, and discovered by empirical and scientific findings, mindfulness in education can be an essential asset in a new education paradigm.

Introducing new initiatives and pedagogies carries new issues. As such, future implementation of mindfulness in educational contexts, including the careful development and introduction of new models, will ideally be accompanied by a simultaneous process of empirical assessment.

Transforming education is not simple or easy. To make a meaningful progress, we need collaboration, creativity, critical thinking, patience, and resilience. We must mobilize changes that are comprehensive and sustainable, and support the transformations of teaching, curriculum, teacher preparation, and school climate and culture. It is time to gather this momentum, ignite transdisciplinary dialogue, and form a unified framework that can shape the lives and performance of children across the world. 


\section{References}

Adler, A. (2016). Teaching well-being increases academic performance: Evidence from Bhutan, Mexico, and Peru. Publicly Accessible Penn Dissertations, University of Pennsylvania, Philadelphia, PA 1572.

Ager, K., Albrecht, N., \& Cohen, M. (2015). Mindfulness in schools research project: Exploring students' perspectives of mindfulness-What are students' perspectives of learning mindfulness practices at school? Psychology, 6(7), 896914.

Albrecht, N. J. (2018). Teachers teaching mindfulness with children: Being a mindful role model. Australian Journal of Teacher Education, 43(10), 1-23.

Arendt, J. F., Verdorfer, A. P., \& Kugler, K. G. (2019). Mindfulness and leadership: Communication as a behavioral correlate of leader mindfulness and its effect on follower satisfaction. Frontiers in Psychology, 10, 667.

Aspen Institute National Commission on Social, Emotional, and Academic Development. (2019). From a nation at risk to a nation at hope.

Bailey, N. W., Owen, J., Hassed, C. S., Chambers, R. H., Jones, A., \& Wootten, A. (2018). Evidence-based guidelines for mindfulness in schools: A guide for teachers and principals.

Bartlett, L., Martin, A., Neil, A. L., Memish, K., Otahal, P., Kilpatrick, M., et al. (2019). A systematic review and meta-analysis of workplace mindfulness training randomized controlled trials. Journal of Occupational Health Psychology, 24(1), 108.

Beltman, S., \& Poulton, E. (2019). “Take a step back": Teacher strategies for managing heightened emotions. The Australian Educational Researcher, 46(4), 661-679.

Berkovich-Ohana, A., Jennings, P. A., \& Lavy, S. (2019). Contemplative neuroscience, self-awareness, and education. In Progress in brain research (Vol. 244, pp. 355-385). Elsevier.

Bernay, R., Graham, E., Devcich, D. A., Rix, G., \& Rubie-Davies, C. M. (2016). Pause, breathe, smile: A mixed-methods study of student well-being following participation in an eight-week, locally developed mindfulness program in three New Zealand schools. Advances in School Mental Health Promotion, 9(2), 90-106.

Beshai, S., McAlpine, L., Weare, K., \& Kuyken, W. (2016). A non-randomised feasibility trial assessing the efficacy of a mindfulness-based intervention for teachers to reduce stress and improve well-being. Mindfulness, 7(1), 198-208.

Bishop, S. R., Lau, M., Shapiro, S., Carlson, L., Anderson, N. D., Carmody, J., ... Devins, G. (2004). Mindfulness: A proposed operational definition. Clinical Psychology: Science and Practice, 11(3), 230-241.

Black, D. S. (2018). Research publications on mindfulness. Retrieved from https://goa mra.org/resources. 
Black, D. S., \& Slavich, G. M. (2016). Mindfulness meditation and the immune system: A systematic review of randomized controlled trials. Annals of the New York Academy of Sciences, 1373(1), 13.

Bluth, K., Gaylord, S. A., Campo, R. A., Mullarkey, M. C., \& Hobbs, L. (2016). Making friends with yourself: A mixed methods pilot study of a mindful selfcompassion program for adolescents. Mindfulness, 7(2), 479-492.

Bodhi, B. (2011). What does mindfulness really mean? A canonical perspective. Contemporary Buddhism, 12(01), 19-39.

Bristow, J. (2019). Mindfulness in politics and public policy. Current Opinion in Psychology, 28, 87-91.

Broderick, P. C. (2013). Learning to breathe: A mindfulness curriculum for adolescents to cultivate emotion regulation, attention, and performance. New Harbinger Publications.

Broderick, P. C., \& Frank, J. L. (2014). Learning to BREATHE: An intervention to foster mindfulness in adolescence. New Directions for Youth Development, 2014(142), 31-44.

Broderick, P. C., Frank, J. L., Berrena, E., Schussler, D. L., Kohler, K., Mitra, J., ... Greenberg, M. T. (2019). Evaluating the quality of mindfulness instruction delivered in school settings: development and validation of a teacher quality observational rating scale. Mindfulness, 10(1), 36-45.

Burnett, R. (2011). Mindfulness in schools: Learning lessons from the adults, secular and Buddhist. Buddhist Studies Review, 28(1), 79-120.

Carlson, L. E. (2012). Mindfulness-based interventions for physical conditions: A narrative review evaluating levels of evidence. ISRN Psychiatry, 2012.

Crain, T. L., Schonert-Reichl, K. A., \& Roeser, R. W. (2017). Cultivating teacher mindfulness: Effects of a randomized controlled trial on work, home, and sleep outcomes. Journal of Occupational Health Psychology, 22(2), 138.

Cullen, M., \& Pons, G. B. (2015). The mindfulness-based emotional balance workbook: An eight-week program for improved emotion regulation and resilience. New Harbinger Publications.

de Carvalho, J. S., Pinto, A. M., \& Marôco, J. (2017). Results of a mindfulnessbased social-emotional learning program on portuguese elementary students and teachers: a quasi-experimental study. Mindfulness, 8(2), 337-350.

Devcich, D. A., Rix, G., Bernay, R., \& Graham, E. (2017). Effectiveness of a mindfulness-based program on school children's self-reported well-being: A pilot study comparing effects with an emotional literacy program. Journal of Applied School Psychology, 33(4), 309-330.

Diamond, A. (2010). The evidence base for improving school outcomes by addressing the whole child and by addressing skills and attitudes, not just content. Early Education and Development, 21(5), 780-793.

Ditrich, T. (2017). The conceptualisation and practice of mindfulness: Buddhist and secular perspectives. Mindfulness and Education: Research and Practice, 3-32.

Drupka, K., \& Brien, K. (2013). Educating for Gross National Happiness: A new paradigm for education in Bhutan. Antistasis, 3(2). 
Dunning, D. L., Griffiths, K., Kuyken, W., Crane, C., Foulkes, L., Parker, J., et al. (2019). Research review: The effects of mindfulness-based interventions on cognition and mental health in children and adolescents-A meta-analysis of randomized controlled trials. Journal of Child Psychology and Psychiatry, 60(3), 244-258.

European Network for Mental Health Promotion. (2009). Manual for promoting mental health and well-being: The educational setting-ProMenPol Project: Author. Retrieved from http://www.mentalhealthpromotion.net/resources/toolitmanuals/manual-for-educational-setting.pdf.

Emerson, L. M., de Diaz, N. N., Sherwood, A., Waters, A., \& Farrell, L. (2020). Mindfulness interventions in schools: Integrity and feasibility of implementation. International Journal of Behavioral Development, 44(1), 62-75.

Emerson, L. M., Leyland, A., Hudson, K., Rowse, G., Hanley, P., \& Hugh-Jones, S. (2017). Teaching mindfulness to teachers: A systematic review and narrative synthesis. Mindfulness, 8(5), 1136-1149.

Ergas, O., \& Avisar, A. (Ed.). (in press). Mindfulness and social emotional learning in teachers education. Tel Aviv: Mofet.

Ergas, O., \& Hadar, L. L. (2019). Mindfulness in and as education: A map of a developing academic discourse from 2002 to 2017. Review of Education, 7, 757-797.

Etty-Leal, J. (2010). Meditation capsules: A mindfulness program for children. Melbourne, VIC: Meditation Capsules.

Felver, J. C., Celis-de Hoyos, C. E., Tezanos, K., \& Singh, N. N. (2016). A systematic review of mindfulness-based interventions for youth in school settings. Mindfulness, 7(1), 34-45.

Felver, J. C., Clawson, A. J., Morton, M. L., Brier-Kennedy, E., Janack, P., \& DiFlorio, R. A. (2019). School-based mindfulness intervention supports adolescent resiliency: A randomized controlled pilot study. International Journal of School \& Educational Psychology, 7(sup1), 111-122.

Felver, J. C., Doerner, E., Jones, J., Kaye, N. C., \& Merrell, K. W. (2013). Mindfulness in school psychology: Applications for intervention and professional practice. Psychology in the Schools, 50(6), 531-547.

Felver, J. C., \& Jennings, P. A. (2016). Applications of mindfulness-based interventions in school settings: An introduction.

Ferrari, M., Hunt, C., Harrysunker, A., Abbott, M. J., Beath, A. P., \& Einstein, D. A. (2019). Self-compassion interventions and psychosocial outcomes: A metaanalysis of RCTs. Mindfulness, 1-19.

Germer, C., Siegel, R. D., \& Fulton, P. R. (Eds.). (2016). Mindfulness and psychotherapy. Guilford Publications.

Germer, G. (2005). What is mindfulness? In G. Germer, R. Siegel, \& P. Fulton (Eds.), Mindfulness and psychotherapy (pp. 1-27). New York: Guilford.

Germer, C. K., \& Neff, K. D. (2013). Self-compassion in clinical practice. Journal of Clinical Psychology, 69(8), 856-867. 
Greenberg, M. T., \& Harris, A. R. (2012). Nurturing mindfulness in children and youth: Current state of research. Child Development Perspectives, 6(2), 161-166.

Greeson, J. M., \& Chin, G. R. (2019). Mindfulness and physical disease: A concise review. Current Opinion in Psychology, 28, 204-210.

Harris, A. R., Jennings, P. A., Katz, D. A., Abenavoli, R. M., \& Greenberg, M. T. (2016). Promoting stress management and well-being in educators: Feasibility and efficacy of a school-based yoga and mindfulness intervention. Mindfulness, $7(1), 143-154$.

Hawn, F. (2011). The mind-up curriculum: Brain-focused strategies for learning and living. New York.

Hayward, K., \& Colman, R. (2010). Educating for GNH. Thimphu, Bhutan: GPI Atlantic. Retrieved from http://www.gpiatlantic.org/pdf/educatingforgnh/educat ing_for_gnh_proceedings.pdf.

Hayward, K., Pannozzo, L., \& Colman, R. (2009). Educating for Gross National Happiness in Bhutan: Developing Curricula and Indicators for an Educated Populace: A Literature Review. Document 2, Parts IV-VI. GPI Atlantic.

Hirshberg, M. J., Flook, L., Enright, R. D., \& Davidson, R. J. (2020). Integrating mindfulness and connection practices into pre-service teacher education improves classroom practices. Learning and Instruction, 66,.

Huppert, F. A., \& Johnson, D. M. (2010). A controlled trial of mindfulness training in schools: The importance of practice for an impact on well-being. The Journal of Positive Psychology, 5(4), 264-274.

Ivtzan, I., \& Lomas, T. (Eds.). (2016). Mindfulness in positive psychology: The science of meditation and well-being. Routledge.

Janz, P., Dawe, S., \& Wyllie, M. (2019). Mindfulness-based program embedded within the existing curriculum improves executive functioning and behavior in young children: A waitlist controlled trial. Frontiers in Psychology, 10, 2052.

Jennings, P. A. (2016). Mindfulness-based programs and the American public school system: Recommendations for best practices to ensure secularity. Mindfulness, 7(1), 176-178.

Jennings, P. A., Doyle, S., Oh, Y., Rasheed, D., Frank, J. L., \& Brown, J. L. (2019). Long-term impacts of the CARE program on teachers' self-reported social and emotional competence and well-being. Journal of School Psychology, 76, 186-202.

Jennings, P. A., \& Greenberg, M. T. (2009). The prosocial classroom: Teacher social and emotional competence in relation to student and classroom outcomes. Review of Educational Research, 79(1), 491-525.

Jennings, P., Lantieri, L., \& Roeser, R. W. (2012). Supporting educational goals through cultivating mindfulness. Handbook of Prosocial Education, 2, 371.

Kabat-Zinn, J. (1990). Full catastrophe living: Using the wisdom of your body and mind to face stress, pain, and illness. USA: Delta.

Kabat-Zinn, J. (2003). Mindfulness-based interventions in context: Past, present, and future. Clinical Psychology: Science and Practice, 10(2), 144-156. 
Kaliman, P. (2019). Lifestyle and well-being: Potential epigenetic benefits of mindfulness training, healthy eating and physical activity. In Enhancing resilience in youth (pp. 39-55). Cham: Springer.

Kaliman, P., Álvarez-López, M. J., Cosín-Tomás, M., Rosenkranz, M. A., Lutz, A., \& Davidson, R. J. (2014). Rapid changes in histone deacetylases and inflammatory gene expression in expert meditators. Psychoneuroendocrinology, 40, 96-107.

Kielty, M. L., Gilligan, T. D., \& Staton, A. R. (2017). Whole-school approaches to incorporating mindfulness-based interventions: Supporting the capacity for optimal functioning in school settings. Childhood Education, 93(2), 128-135.

King, A. P. (2019). Mindfulness-based workplace interventions for wellness promotion. Mental Health in the Workplace: Strategies and Tools to Optimize Outcomes, 191.

Klingbeil, D. A., \& Renshaw, T. L. (2018). Mindfulness-based interventions for teachers: A meta-analysis of the emerging evidence base. School Psychology Quarterly, 33(4), 501.

Klingbeil, D. A., Renshaw, T. L., Willenbrink, J. B., Copek, R. A., Chan, K. T., Haddock, A., ... Clifton, J. (2017). Mindfulness-based interventions with youth: A comprehensive meta-analysis of group-design studies. Journal of School Psychology, 63, 77-103.

Kuyken, W., Nuthall, E., Byford, S., Crane, C., Dalgleish, T., Ford, T., ... Williams, J. M. G. (2017). The effectiveness and cost-effectiveness of a mindfulness training programme in schools compared with normal school provision (MYRIAD): Study protocol for a randomised controlled trial. Trials, 18(1), 194.

Kuyken, W., Weare, K., Ukoumunne, O. C., Vicary, R., Motton, N., Burnett, R., ... Huppert, F. (2013). Effectiveness of the mindfulness in schools programme: Non-randomised controlled feasibility study. The British Journal of Psychiatry, 203(2), 126-131.

Langford, R., Bonell, C. P., Jones, H. E., Pouliou, T., Murphy, S. M., Waters, E., ... Campbell, R. (2014). The WHO Health Promoting School framework for improving the health and well-being of students and their academic achievement. Cochrane Database of Systematic Reviews (4).

Lombas, A. S., Jiménez, T. I., Arguís-Rey, R., Hernández-Paniello, S., Valdivia-Salas, S., \& Martín-Albo, J. (2019). Impact of the happy classroom programme on psychological well-being, school aggression, and classroom climate. Mindfulness, $1-19$.

Lomas, T., Medina, J. C., Ivtzan, I., Rupprecht, S., \& Eiroa-Orosa, F. J. (2017). The impact of mindfulness on the well-being and performance of educators: A systematic review of the empirical literature. Teaching and Teacher Education, 61, 132-141.

Lyubomirsky, S., \& Layous, K. (2013). How do simple positive activities increase well-being? Current Directions in Psychological Science, 22(1), 57-62.

Maloney, J. E., Lawlor, M. S., Schonert-Reichl, K. A., \& Whitehead, J. (2016). A mindfulness-based social and emotional learning curriculum for school-aged 
children: The MindUP program. In Handbook of mindfulness in education (pp. 313-334). New York, NY: Springer.

Maynard, B. R., Solis, M., \& Miller, V. (2015). Mindfulness-based interventions for improving academic achievement, behavior and socio-emotional functioning of primary and secondary students: A systematic review. Campbell Library. Retrieved from http://www.campbellcollaboration.org/lib/project/342/.

McKeering, P., \& Hwang, Y. S. (2019). A systematic review of mindfulness-based school interventions with early adolescents. Mindfulness, 10(4), 593-610.

Meiklejohn, J., Phillips, C., Freedman, M. L., Griffin, M. L., Biegel, G., Roach, A., ... Isberg, R. (2012). Integrating mindfulness training into K-12 education: Fostering the resilience of teachers and students. Mindfulness, 3(4), 291-307. A Training Manual.

Metz, S. M., Frank, J. L., Reibel, D., Cantrell, T., Sanders, R., \& Broderick, P. C. (2013). The effectiveness of the learning to BREATHE program on adolescent emotion regulation. Research in Human Development, 10(3), 252-272.

Mindful Schools. (2015). Curriculum training. Retrieved from http://www.mindfu lschools.org/training/curriculum-training.

Ministry of Education, Royal Government of Bhutan. (2013). Educating for Gross National Happiness.

National Commission on Social, Emotional, and Academic Development. (2019). From a nation at risk to a nation at hope: Recommendations from the National Commission on Social, Emotional, and Academic Development.

Niemiec, R. M. (2013). Mindfulness and character strengths. Hogrefe Publishing.

Norrish, J. M. (2015). Positive education: The Geelong grammar school journey. Oxford Positive Psychology Series.

NSW Government. (2015). The well-being framework for schools. Sydney, NSW: Department of Education and Communities. Retrieved 3 February 2020, from https://www.det.nsw.edu.au/wellbeing/about/16531_Wellbeing-Fra mework-forschools_Acessible.pdf.

OECD. (2018). The future of education and skills: Education 2030. OECD Education 2030.

Olness, K., \& Kohen, D. P. (1996). Hypnosis and hypnotherapy with children.

Parker, A. E., Kupersmidt, J. B., Mathis, E. T., Scull, T. M., \& Sims, C. (2014). The impact of mindfulness education on elementary school students: Evaluation of the Master mind program. Advances in School Mental Health Promotion, 7(3), 184-204.

Pollak, S. M., Pedulla, T., \& Siegel, R. D. (2014). Sitting together: Essential skills for mindfulness-based psychotherapy. Guilford Publications.

Rappaport, L. (2008). Focusing-oriented art therapy: Accessing the body's wisdom and creative intelligence. Jessica Kingsley Publishers.

Rawana, J. S., Diplock, B. D., \& Chan, S. (2018). Mindfulness-based programs in school settings: Current state of the research. In Handbook of school-based mental health promotion (pp. 323-355). Cham: Springer. 
Rivkin, S. G., Hanushek, E. A., \& Kain, J. F. (2005). Teachers, schools, and academic achievement. Econometrica, 73(2), 417-458.

Roeser, R. W., Skinner, E., Beers, J., \& Jennings, P. A. (2012). Mindfulness training and teachers' professional development: An emerging area of research and practice. Child Development Perspectives, 6(2), 167-173.

Ryan, R. M., \& Deci, E. L. (2000). Self-determination theory and the facilitation of intrinsic motivation, social development, and well-being. American Psychologist, 55(1), 68.

Schleicher, A. (2018). World class: How to build a 21st-century school system, Strong Performers and Successful Reformers in Education. OECD Publishing.

Schonert-Reichl, K. A., Oberle, E., Lawlor, M. S., Abbott, D., Thomson, K., Oberlander, T. F., et al. (2015). Enhancing cognitive and social-emotional development through a simple-to-administer mindfulness-based school program for elementary school children: A randomized controlled trial. Developmental Psychology, 51(1), 52.

Schonert-Reichl, K. A., \& Roeser, R. W. (Eds.). (2016). Handbook of mindfulness in education: Integrating theory and research into practice. Springer.

Schussler, D. L., Greenberg, M., DeWeese, A., Rasheed, D., DeMauro, A., Jennings, P. A., et al. (2018). Stress and release: Case studies of teacher resilience following a mindfulness-based intervention. American Journal of Education, 125(1), 1-28.

Schwartz, R. C. (2013). Moving from acceptance toward transformation with internal family systems therapy (IFS). Journal of Clinical Psychology, 69(8), 805-816.

Segal, Z. V., Williams, J. M. G., \& Teasdale, J. D. (2013). Mindfulness-based cognitive therapy for depression.

Semple, R., \& Burke, C. (2019). State of the research: Physical and mental health benefits of mindfulness-based interventions for children and adolescents. $O B M$ Integrative and Complementary Medicine, 4(1), 1-31.

Semple, R. J., Droutman, V., \& Reid, B. A. (2017). Mindfulness goes to school: Things learned (so far) from research and real-world experiences. Psychology in the Schools, 54(1), 29-52.

Semple, R. J., \& Lee, J. (2014). Mindfulness-based cognitive therapy for children. In Mindfulness-based treatment approaches (pp. 161-188). Academic Press.

Shapiro, S., de Sousa, S., \& Jazaieri, H. (2016). Mindfulness, mental health, and positive psychology. In Mindfulness in positive psychology (pp. 118-135). Routledge.

Sheinman, N., \& Hadar, L. L. (2017). Mindfulness in education as a whole of school approach: Principles, insights and outcomes. Mindfulness and Education: Research and Practice, 77-101.

Sheinman, N., Hadar, L. L., Gafni, D., \& Milman, M. (2018). Preliminary investigation of whole-school mindfulness in education programs and children's mindfulness-based coping strategies. Journal of Child and Family Studies, 27(10), 3316-3328. 
Sherab, K., Cooksey, R., \& Maxwell, T. W. (2014). Gross national happiness education in Bhutanese schools: Understanding the experiences and efficacy beliefs of principals and teachers.

Shonin, E., Van Gordon, W., \& Griffiths, M. (2013). Mindfulness-based interventions: Towards mindful clinical integration. Frontiers in Psychology, 4, 194.

Singh, N. N., Lancioni, G. E., Winton, A. S., Adkins, A. D., Wahler, R. G., Sabaawi, M., \& Singh, J. (2007). Individuals with mental illness can control their aggressive behavior through mindfulness training. Behavior modification, 31(3), 313-328.

Slade, S., \& Griffith, D. (2013). A whole child approach to student success. KEDI Journal of Educational Policy, 10(3).

Smiling Mind. (2017). Establishing an evidence base for the Smiling Mind Education Program. Retrieved from https://static1.squarespace.com/static/5a2f40a $41 \mathrm{f3} 18 \mathrm{~d} 3$ 8ccf0c819/t/5a8e1e78e4966bbc8ab648ff/1519263376896/research-project-rep ort.pdf.

Stewart-Brown, S. (2006). What is the evidence on school health promotion in improving health or preventing disease and, specifically, what is the effectiveness of the health promoting schools approach? World Health Organization.

Tang, Y. Y., Hölzel, B. K., \& Posner, M. I. (2015). The neuroscience of mindfulness meditation. Nature Reviews Neuroscience, 16(4), 213.

Tarrasch, R., Berger, R., \& Grossman, D. (2020). Mindfulness and compassion as key factors in improving teacher's well being. Mindfulness, 1-13.

The Mindfulness Initiative: Health, Wellbeing and Mindfulness. Retrieved from https://www.themindfulnessinitiative.org/Handlers/Download.ashx?IDMF=6e5 43eb7-c5b6-4d3c-a537-6a2961965887.

UNESCO. (1972). Learning to be: The world of education today and tomorrow. Report of the International Commission on Education.

UNESCO. (1996). Learning: The treasure within. UNESCO.

UNESCO. (2015). Rethinking education: Towards a global common good. UNESCO.

UNESCO. (2019). Futures of education: learning to become. Retrieved from https:// www.unesdoc.unesco.org/ark.

Walsh, R. (1983). Meditation practice and research. Journal of Humanistic Psychology, 23(1), 18-50.

Weare, K. (2014). Evidence for mindfulness: Impacts on the wellbeing and performance of school staff. https://mindfulnessinschools.org/wp-content/uploads/2014/10/ Evidence-for-Mindfulness-Impact-on-school-staff.pdf.

Weare, K. (2019). Mindfulness and contemplative approaches in education. Current Opinion in Psychology.

Weiss, H., Johanson, G., \& Monda, L. (2015). Hakomi mindfulness-centered somatic psychotherapy: A comprehensive guide to theory and practice. W.W. Norton \& Company.

World Health Organization. (1999). Partners in life skills education. Geneva, Switzerland: World Health Organization, Department of Mental Health. 
World Health Organization. (n.d.). School and youth health: What is a healthpromoting school? Retrieved from http://www.who.int/school_youth_health/gshi/ hps/en/.

Young, S. (2016). What is mindfulness? A contemplative perspective. In Handbook of mindfulness in education (pp. 29-45). New York, NY: Springer.

Zarate, K., Maggin, D. M., \& Passmore, A. (2019). Meta-analysis of mindfulness training on teacher well-being. Psychology in the Schools, 56(10), 1700-1715.

Zenner, C., Herrnleben-Kurz, S., \& Walach, H. (2014). Mindfulness-based interventions in schools - a systematic review and meta-analysis. Frontiers in psychology, 5, 603.

Zins, J. E., Bloodworth, M. R., Weissberg, R. P., \& Walberg, H. J. (2007). The scientific base linking social and emotional learning to school success. Journal of Educational and Psychological Consultation, 17(2-3), 191-210.

Open Access This chapter is licensed under the terms of the Creative Commons Attribution 4.0 International License (http://creativecommons.org/licenses/by/4.0/), which permits use, sharing, adaptation, distribution and reproduction in any medium or format, as long as you give appropriate credit to the original author(s) and the source, provide a link to the Creative Commons license and indicate if changes were made.

The images or other third party material in this chapter are included in the chapter's Creative Commons license, unless indicated otherwise in a credit line to the material. If material is not included in the chapter's Creative Commons license and your intended use is not permitted by statutory regulation or exceeds the permitted use, you will need to obtain permission directly from the copyright holder.

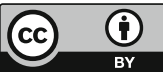

